Recepción: Septiembre 13, 2020 | Aceptación: Septiembre 28, 2020

\title{
EVIDENCIAS CIENTIIFICAS DE LA SOBREVIVENCIA DEL SARS COV-2 EN AGUA DE GRIFO NO CONTAMINADA Y EN AGUAS RESIDUALES NO TRATADAS ${ }^{1}$
}

SCIENTIFIC EVIDENCE OF SURVIVAL SURVIVAL OF SARS COV-2 IN UNPOLLUTED TAP WATER AND UNTREATED WASTEWATER

Martín D. Mundo Molina ic_ingenieros@yahoo.com.mx

\section{CENTRO DE INVESTIGACIÓN DE LA FACULTAD DE INGENIERÍA UNIVERSIDAD AUTÓNOMA DE CHIAPAS, MÉXICO}

1 Este ensayo se realizó con la evidencia científica disponible hasta su publicación, por lo tanto, los datos de investigación sobre la COVID-19 y el SARS CoV-2, son válidos hasta la fecha de su publicación, en tanto las investigaciones científicas corroboren o refuten los argumentos enunciados. 
Para citar este artículo:

Mundo Molina, M. D. (2020). Evidencias científicas de la sobrevivencia del SARS CoV-2 en agua de grifo no contaminada y en aguas residuales no tratadas. ESPACIO $1+D$, INNOVACIÓN MÁS DESARROLLO, 9(25). https://doi.org/10.31644/IMASD.25.2020.a11

\section{RESUMEN}

Los problemas de contaminación por residuos sólidos urbano-rurales, que sufren los arroyos, ríos, lagunas, lagos y embalses de presas en México, sumado a la recepción permanente de aguas residuales sin tratar, de miles de centros de población y comunidades anexas distribuidas a lo largo y ancho del territorio nacional, se traducen en problemas de polución del medio ambiente y riesgos para la salud humana. Se destaca el poco o nulo esfuerzo efectivo que las instituciones del sector hacen para evitar esta problemática, a pesar de las obligaciones y exigencias que las leyes correspondientes les imponen. En ese marco de referencia, se presenta como principal argumento un problema adicional, que se evidenciará en cada ciclo recurrente de epidemias y pandemias que la nación sufra en el futuro: la presencia de ciertos tipos de virus mórbidos y su sobrevivencia en las aguas contaminadas y libres de contaminación del país. En este caso en particular y a la sazón de las circunstancias recientes, en este documento se presentan, además, las evidencias científicas de la sobrevivencia del SARS CoV-2 en agua de grifo no contaminada y en aguas residuales no tratadas, que debería no solo preocupar sino impulsar la actuación del sector institucional ambiental e hídrico de México, por el riesgo que este problema representa, no solo para el medio ambiente, sino para la salud humana.

\section{Palabras Clave:}

SARS CoV-2, COVID, contaminación, residuos sólidos, aguas residuales, ley de aguas nacionales. 


\section{- Abstract-}

The problems caused by urban-rural solid waste pollution, affect streams, rivers, lagoons, lakes and dam reservoirs in Mexico, is added the permanent reception of wastewater without treatment, of thousands of populated areas and communities distributed throughout the national territory. The little or no effective effort that the sector institutions do to avoid this problem is highlighted, despite the obligations and requirements imposed by law. In that frame of reference, it is presented as a principal argument an additional problem, that will be evidenced in each recurrent cycle of epidemics and pandemics that the nation may suffer in the future: the presence of certain types of morbid viruses and their survival in polluted waters and un-polluted waters of the nation. In this particular case, and at the time of recent circumstances, this document also presents, the scientific evidence of the survival of SARS CoV-2 in un-polluted tap water and in un-treated waste water, which should not only concern but to promote the actions of the environmental and water institution of Mexico, because of the risk that this problem represents, not only for the environment, but for human health.

\section{Key Words:}

SARS CoV-2, COVID, pollution, solid waste, waste water, National Water Law. 
A

ctualmente COVID es la palabra con más menciones diarias, no solo en los diálogos familiares sino en todos los sistemas de comunicación alrededor del mundo: periódicos, radio, televisión, redes sociales (internet) y las aplicaciones móviles de smartphones o tablets. De acuerdo a la BBC (2020) en un solo día, el II de marzo de 2020, este vocablo fue buscado 20 millones de veces a través de Google, Facebook y Twitter. Las cifras son congruentes con los datos mostrados en la hoja informativa de la Organización Panamericana de la Salud (OPS) la que enunció que en marzo de 2020 la palabra COVID se envió por Twitter 550 millones de veces (incluyéndose términos como coronavirus, corona virus, covid 19, covid-19, covid_19 o pandemia), mientras que en el mes de abril se anexaron a YouTube 36I,000,000 de videos en la categoría de la COVID-19 y desde que comenzó la pandemia se han publicado más de 19,200 artículos en Google Scholar (OPS, 2020b). A pesar de tanta información (la OPS la denominó infodemic'), millones de usuarios alrededor del mundo ignoran, entre otras cosas: de qué tamaño promedio es el virus, cómo es el virus visto desde un microscopio electrónico (foto I), el significado del vocablo COVID o los riesgos que la presencia del ARN de este virus tiene en el agua de grifo no contaminada y en las aguas residuales no tratadas. En la foto I se pueden ver dos imágenes, la primera es una idealización del virus de la COVID-19, tomada en el Center for Disease Control and Prevention del Gobierno de los Estados Unidos de Norteamérica y la segunda es una foto del virus visto desde un microscopio electrónico, en donde se puede apreciar hasta cuatro coronavirus (tomada de la muestra de un paciente estadounidense, el pasado I 2 de febrero de 2020).

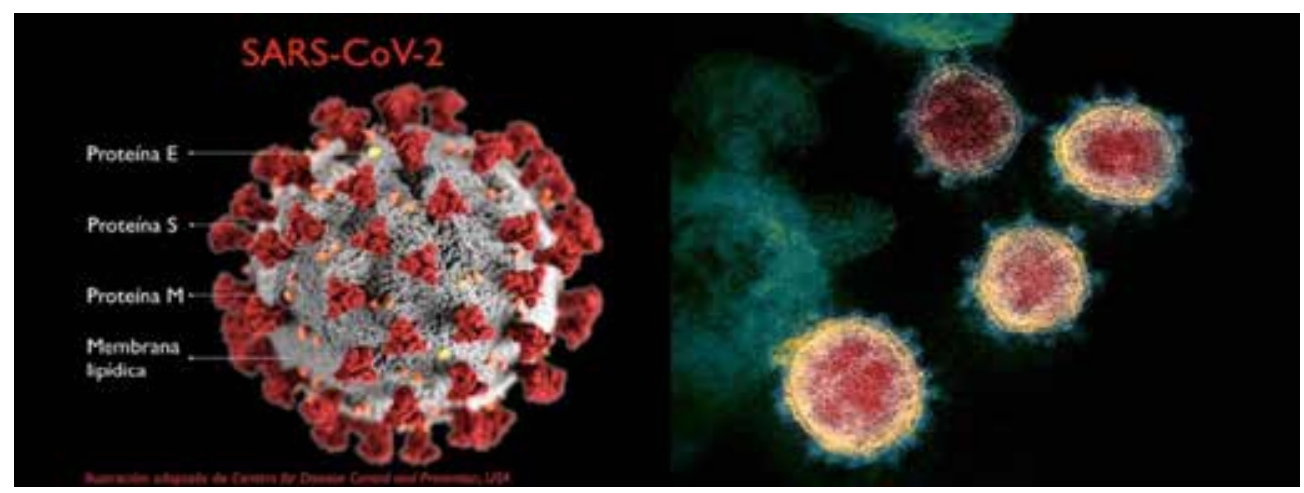

Foto 1. Idealización y foto de cuatro coronavirus (de un paciente de USA). Fuente: CDCP,2020; NGE, 2020

1 Infodemic es un vocablo que no se encuentra en los siguientes diccionarios: Oxford Englis Dictionary, Cambridge Advanced Learner's Dictionary, Webster's New World Dictionary. El término en inglés lo tradujo la OPS (2020b) al español como infodemia en su informe: "Entender la infodemia y la desinformación en la lucha contra el coronavirus". Infodemia es un neologismo que a la fecha no está reconocido por la RAE (2001) y en ninguna versión posterior. Se sugiere utilizar la palabra "bulo" para sustituir a "infodemia". Sobre este tema se recomienda leer a Salaverría et al., (2020), quienes realizaron una investigación formal sobre el tema. 
En cuanto a su tamaño, las imágenes obtenidas por micrografías electrónicas del virus SARS CoV-2 muestran una forma esférica con algo de pleomorfismo, con un diámetro entre 0.06 y 0.14 micras (Zhu et al, 2020), con promedio aproximado de 0.125 micras. Esto significa que las partículas del coronavirus son más pequeñas que las partículas PM2.5-10, pero más grandes que algunas partículas de polvo y gases (figura I). Las PMIO o partículas gruesas (PM2.5-10) también llamadas partículas inhalables, son partículas menores a 10 micrómetros pero más grandes que 2.5 micrómetros de diámetro; se consideran partículas contaminantes constituidas por material líquido y sólido de muy diversa composición que se encuentran en el aire (Tzintzun et al, 2005). Por lo tanto, el tamaño del coronavirus es de 0.1 micras, es decir de entre 70 y 166 veces menor que una partícula PM2.5-10. Para dar una idea más realista del caso, si se toma en cuenta que el diámetro promedio de un cabello humano grueso es de es de 170 micras y el coronavirus mostrado en la figura I es de 0 .I micras, entonces en una sección transversal de dicho cabello cabrían casi dos millones novecientos mil coronavirus, mientras que en un cabello fino de 15 micras cabrían más de veintidós mil quinientos coronavirus.

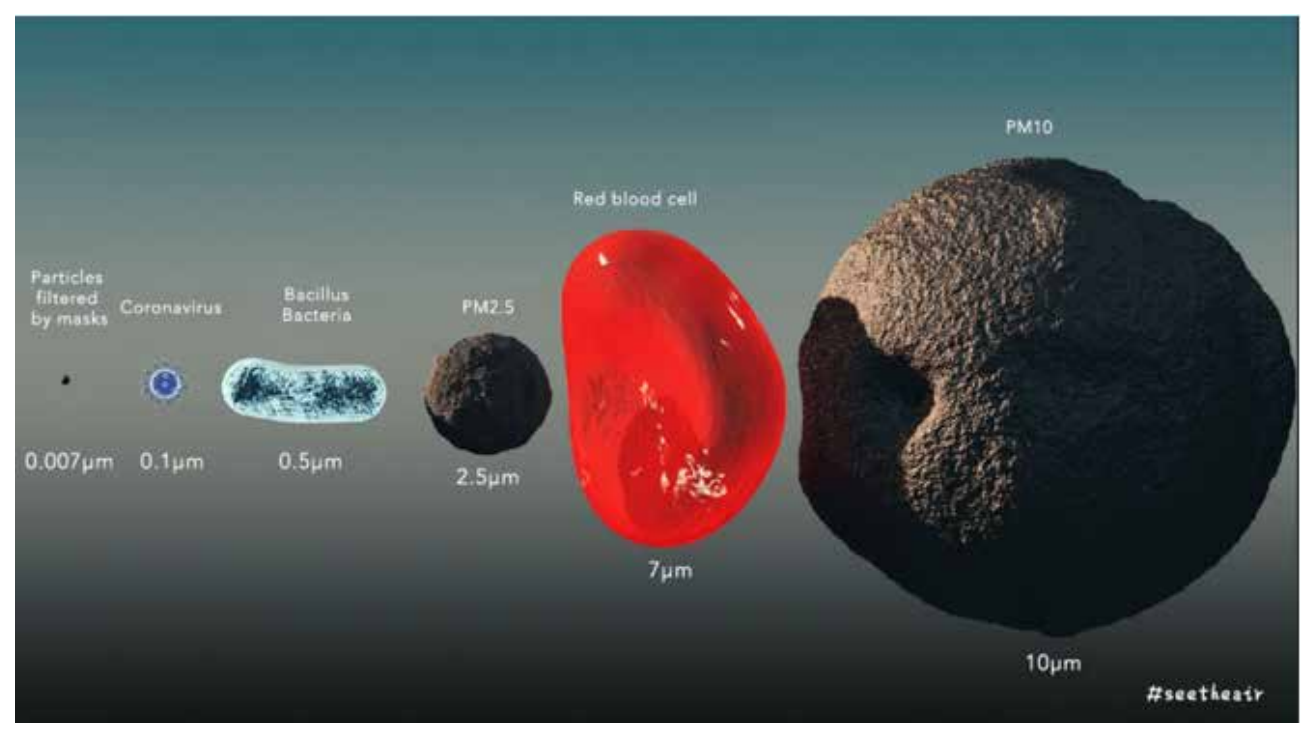

Figura 1. Comparación del tamaño del coronavirus con partículas ambientales PM10. Fuente: Abcdust, 2020

Por otra parte, la palabra COVID es un acrónimo que proviene del inglés y los fonemas que la componen significan COVI (coronavirus) y D (disease). Por lo tanto, la Coronavirus Disease o la COVID- 19 es la enfermedad producida por el coronavirus que surgió en China en el año $2019 . \mathrm{El}$ coronavirus carece de género, sin embargo, de la traducción del acrónimo, de acuerdo a la fonética y teniendo como referencia las reglas de la sintaxis y el sujeto de la frase (enfermedad), se debe escribir o enunciar como: 
la COVID. La COVID-I 9 en términos científicos y refiriéndose al virus, se denomina SARS-CoV-2, que es el acrónimo Severe Acute Respiratory Syndrome Coronavirus 2 (Folegatti et al, 2020). El SARS-CoV-2 se manifestó por primera vez en la ciudad de Wuhan, Hubei, en la República Popular de China, generando un brote epidémico de neumonía de origen desconocido, así lo informó el 19 de diciembre de 2019 un hospital de aquella ciudad, indicando que cuatro individuos tenían neumonía atípica (OPS, 2020a). El 31 de diciembre de ese mismo año, la Comisión Municipal de Salud y Sanidad de Wuhan informó sobre un grupo de 27 casos de neumonía de etiología desconocida (que incluían siete casos graves), que habían tenido una exposición común en un mercado mayorista de pescado, mariscos y animales vivos de aquella ciudad (foto 2 ).

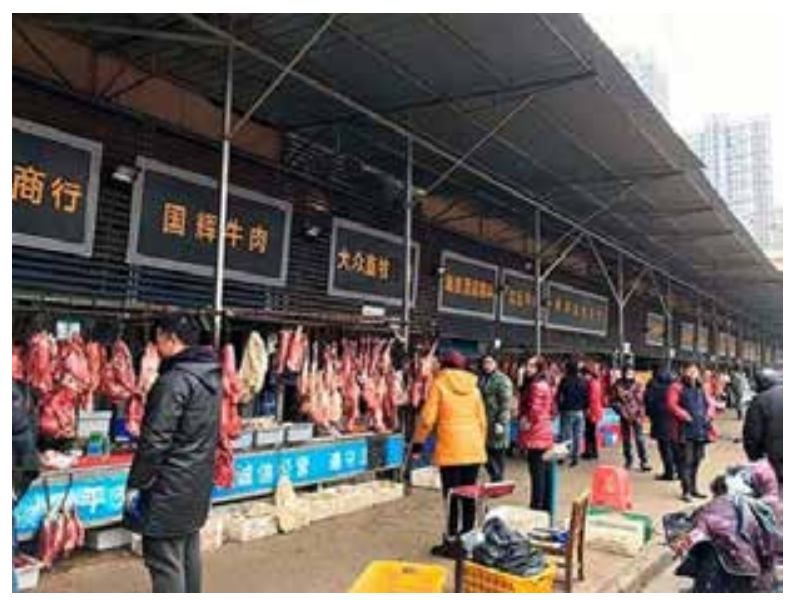

Foto 2. Mercado de abasto de Wuhan, Hubei, China. Fuente: DTNext, 2020

El inicio de los síntomas del primer caso fue el 8 de diciembre de 2019, el individuo infectado tuvo fiebre, tos seca, disnea y hallazgos radiológicos de infiltrados pulmonares bilaterales (SGS, 2020). Entre el 3I de diciembre de 2019 y el 28 de febrero de 2020 se notificaron 83,63 I casos confirmados por laboratorio, infectados de SARS CoV-2, para ese entonces ya se habían producido 2858 muertes en 5 I países del mundo. La mayoría de los casos (94\%) y muertes (98\%) se suscitaron en China, en la provincia de Hubei. De acuerdo a las investigaciones de una misión conjunta de la OMS y China, el brote epidémico alcanzó su punto máximo el 25 de febrero de 2020 (OPS, 2020b). Así, el 7 de enero de 2020, las autoridades identificaron como agente causante del brote un nuevo tipo de virus de la familia Coronaviridae cuya secuencia genética fue compartida por las autoridades chinas el 12 de enero de 2020 (SGS, 2020). El Director General de la Organización Mundial de la Salud (OMS) declaró que el brote era una emergencia de salud pública de importancia internacional y no fue sino hasta el II de febrero de 2020 en que la OMS denominó a esta enfermedad COVID-19 (SGS, 2020). 
Este virus es el séptimo coronavirus conocido con la capacidad de infectar a humanos (Torres, 2020) y de acuerdo a Andersen et al (2020) tiene dos orígenes probables: I. La selección natural en un animal huésped antes de la zoonosis y 2. La selección natural en humanos tras la transferencia zoonótica. El riesgo de contagio de este virus es muy alto y su propagación se aceleró debido al intercambio social directo que la humanidad tiene en su dinámica actual (comerciales, turísticas, académicas, familiares, entre otras). Así, la rápida propagación de este virus por el mundo se debe a la inmensa red de conexiones del planeta (figura 2) y a modo de ejemplo se enuncian los siguientes datos: de acuerdo al comunicado número 45 de la Asociación Internacional de Transporte Aéreo (IATA, 2019) durante el 2018 se trasportaron 4400 millones de pasajeros, a través de una red de 22,000 pares de ciudades conectadas por vuelos directos. Solo las aerolíneas de Asia-Pacífico transportaron 1600 millones de pasajeros, seguida de Europa con I 100 millones de personas, luego de Norteamérica con 989.4 millones de viajeros, finalmente de las compañías latinoamericanas con 302.2 millones de pasajeros.

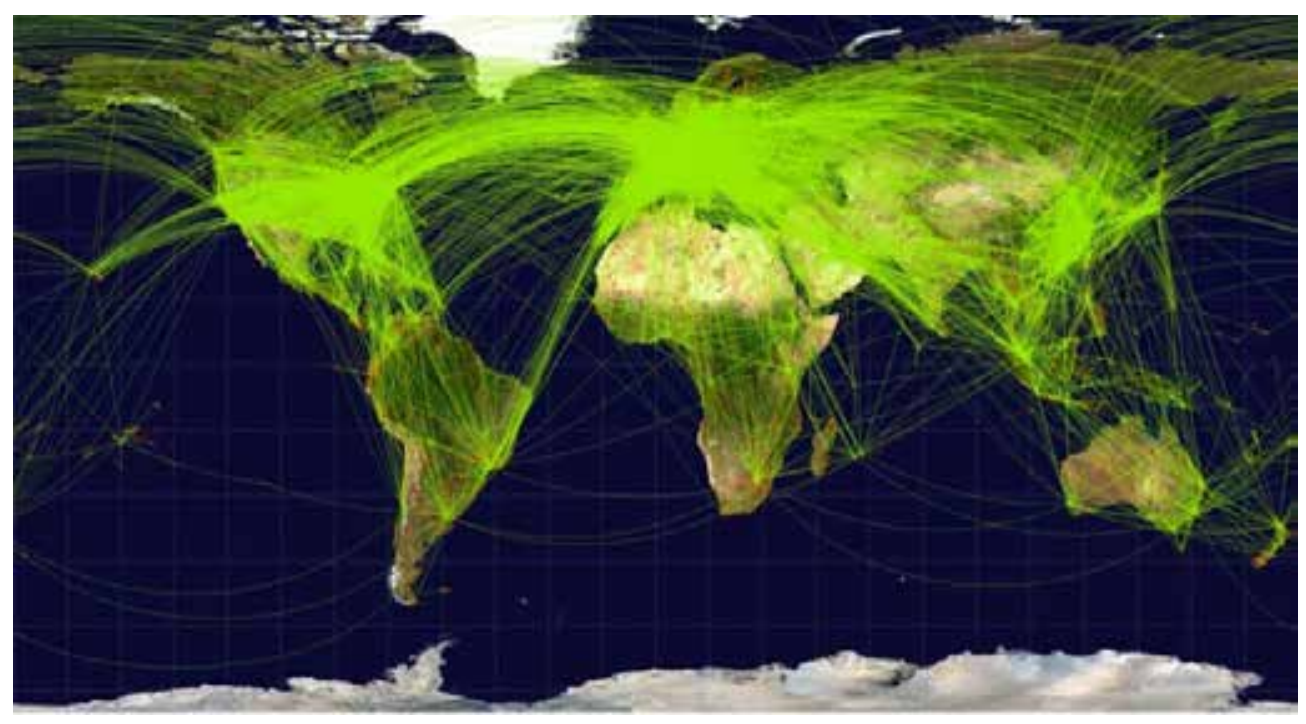

Figura 2. Conexiones aéreas. Fuente: Ramón, 2019

Esta inmensa red de comunicación global generó que casi de forma inmediata el virus se propagara por todos los continentes. El 30 de enero de 2020, en China ya habían más de 9,700 casos confirmados, mientras que se habían corroborado ciento seis casos en diecinueve países (OPS, 2020b). A finales de febrero de 2020, cincuenta países de las seis Regiones de la OMS informaron sobre casos comprobados en las siguientes demarcaciones (figura 3): la Región del Pacífico Occidental (WPRO, ocho países, excluyendo China), la Región Sudeste (SEARO, cuatro países), la Región de las Américas (AMRO, 
cuatro países), la Región Europea (EURO, veintidós países), la Región del Mediterráneo Oriental (EMRO, diez países) y la Región de África (AFRO, dos países), sumando los casos del crucero Diamond Princess (setecientos cinco casos, incluidas cuatro muertes).

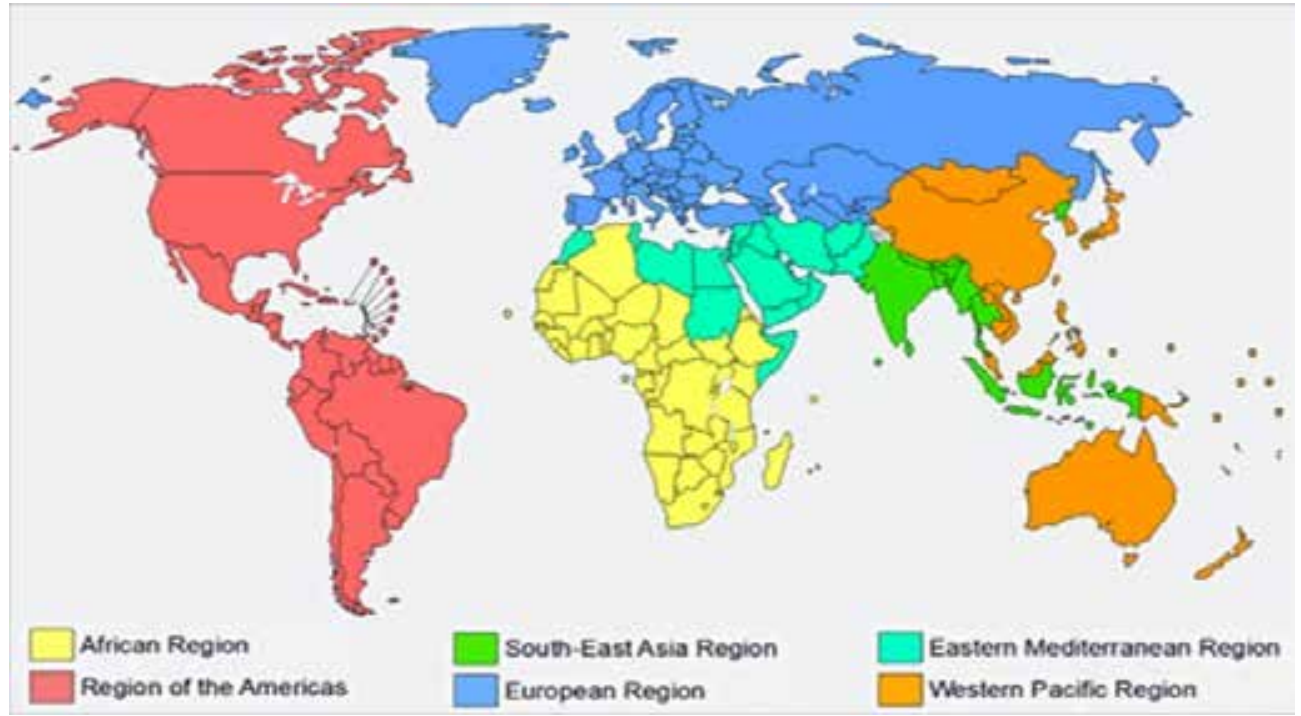

Figura 3. Regiones de la Organización Mundial de la Salud. Fuente: OMS, 2020

Así, con base en esta gigantesca red global de comunicación aérea, el ser humano se desplaza de manera rápida de un lugar a otro, de un continente a otro, pero a todos los sitios a donde el hombre va, tiene que usar agua, si es para beber, ésta debe tener cierta calidad según el país y las normas nacionales o internacionales vigentes. El consumo de agua simple de forma directa o a través de los alimentos tiene relevancia primordial para la salud del viajero o del residente, que además utiliza el líquido vital para diversos usos, entre los más relevantes: aseo personal, limpieza de hábitat (temporal o permanente), indumentaria, enseres personales y el desecho de sus deposiciones. Luego de ser usada, el agua servida se conduce al sistema de drenaje para su tratamiento y/o disposición final (en México normalmente se descarga a los cuerpos de agua). En el agua residual no solo se concentran las aguas utilizadas en las diferentes actividades humanas e industriales, sino también las deposiciones de las viviendas de una comunidad, de los hospitales y/o centros médicos de un territorio. Estas aguas deben ser estudiadas en épocas de epidemias y/o pandemias por el riesgo potencial que representan para el medio ambiente. Sin embargo, las aguas residuales no solo contaminan al medio ambiente, pueden amenazar no solamente a la salud sino a la vida de las personas, al contaminar pozos, arroyos, ríos, lagos, lagunas, acuíferos y zonas marinas, por lo tanto, estas aguas deben ser investigadas. 


\section{ANTECEDENTES}

\section{EI SARS CoV-2 y la COVID-19}

Hasta antes de la aparición de la COVID-19 se conocían un total de 36 coronavirus pertenecientes a la familia coronaviridae. Son virus de tipo ARN positivo de cadena simple, envueltos en una cápside (conjunto de proteínas que envuelven el material genético del SARS CoV-2) que pueden afectar un amplio rango de animales e incluso a humanos (Wertheim et al, 20 I3); fueron descritos por primera vez por Tyrell y Byone en 1966 (Velapam et al, 2020). Basados en su morfología de viriones esféricos con una coraza y proyecciones desde su superficie asemejándose a una corona, fueron llamados coronavirus (WHO, 2020). Los coronavirus son clasificados en cuatro subfamilias, alfa, beta, gamma y delta coronavirus, siendo los alfa y beta originados aparentemente en algunos mamíferos, específicamente en los murciélagos; mientras que los gamma y delta proviene de cerdos y aves (Koury et al, 2020). La identificación del SARS (Peiris et al, 2003) provocó una búsqueda intensiva que resultó en la detección de nuevos coronavirus en seres humanos, animales domésticos y de vida silvestre (Woo et al, 2009). La vigilancia de animales salvajes condujo al descubrimiento de una diversidad de coronavirus en especies de murciélagos y aves, lo que sugiere que estos animales son los reservorios naturales de este tipo de virus (Vijaykrishna et al, 2007). Por un lado, los estudios filogenéticos de coronavirus de murciélagos y aves sugieren una relación antigua con la posible codivergencia y coevolución de sus anfitriones, sin embargo, otros (que se encuentran en murciélagos y otros mamíferos) aluden a que éstos fueron el resultado de recientes eventos de transmisión entre especies (Wertheim et al, 20l3).

Los coronavirus causan infecciones respiratorias e intestinales en animales y personas, pero no se habían considerado altamente patógenos para los humanos hasta la aparición de la epidemia del Síndrome Respiratorio Agudo Severo (SARS) en el 2002 y 2003 en la provincia de Guangdong en China (Wertheim et al, 20I3). Hasta ese momento, las infecciones causadas por coronavirus en humanos solo generaban infecciones leves en pacientes inmunocompetentes (Zhong et al, 2003). La epidemia de SARS pudo ser controlada en poco tiempo y con pocas víctimas mortales. En total, hubo un aproximado de 8096 casos comprobados en 29 países que dejaron un saldo de 774 personas fallecidas (Marty et al, 2020). Diez años después, en el año 2012, emergió otro coronavirus altamente patógeno en países del Medio Este, identificado por primera vez en Arabia Saudita, el Coronavirus causante del Síndrome Respiratorio del Medio Este (MERS-CoV); ambos, el SARS-CoV y MERS-CoV, fueron transmitidos de animales a humanos, de una civeta y un camello respectivamente (aunque hay evidencias de la 
transmisión de humanos a camellos), pero se piensa que ambos virus fueron originados en murciélagos (Marty et al, 2020).

Desde la aparición del SARS en 2002, se han descubierto un gran número de coronavirus relacionados al SARS-CoV en murciélagos, éstos son uno de los reservorios naturales de estos virus (Li et al, 2005). En enero de 2020 se reportó la identificación y caracterización del nuevo coronavirus (20l9-nCoV), así como la secuencia genética de éste, confirmando que compartía el $79.6 \%$ del genoma con el SARS-CoV causante de la epidemia de hace 18 años. Adicionalmente, se pudo identificar que el virus es idéntico en $96 \%$ de su genoma a los coronavirus provenientes de una especie de murciélagos (Zhou et al, 2020). Así, el Grupo de Estudio de Coronavirus del Comité internacional de Taxonomía de Virus, responsable de clasificar y nombrar oficialmente a estos virus, basado en la filogenia, taxonomía y prácticas establecidas, reconocieron formalmente que el 2019-nCoV es hermano de los coronavirus causantes del Síndrome Respiratorio Agudo Severo (SARS-CoVs), de la especie de los coronavirus relacionados al SARSCOV-2 (Gorbalenya et al, 2020). El SARS-CoV-2 pertenece al grupo de los beta coronavirus y está estrechamente relacionado con el SARS-CoV (Velapam et al, 2020). De la misma manera que el SARS-CoV, el SARS-CoV-2 se transmite de persona a persona por contacto directo o indirecto con secreciones respiratorias o fómites, al estornudar o toser, por lo tanto, la mejor manera de evitar la propagación de la enfermedad es el aislamiento de los pacientes que presenten los síntomas.

\section{RIEGOS POTENCIALES DE LA PRESENCIA DE MATERIAL GENÉTICO DEL SARS COV-2 EN EL AGUA}

\section{Material genético del SARS CoV-2 en las aguas residuales}

Con relación a la COVID-19 y a las aguas residuales Cabrerizo et al (2020) afirmaron que el tracto gastrointestinal puede verse afectado por el SARS CoV-2. Se han encontrado pruebas de material genético del virus en heces de pacientes que se infectaron por esa enfermedad y que es excretado y transportado por las aguas residuales. Diferentes estudios han demostrado que el RNA del SARS CoV-2 está presente en las heces de pacientes con la COVID-19, independientemente de la gravedad de la enfermedad (Cabrerizo et al, 2020; Pan, et al, 2020; Wang et al, 2020; Chen et al, 2020; Lescure et al, 2020; Zhang J.C., et al, 2020; Zhang, W., et al, 2020). En 29 de las 35 publicaciones científicas analizadas se reportaron que de 6000 pacientes con SARS CoV-2 estudiados, un 15\% presentó síntomas gastrointestinales, siendo los más comunes: las náuseas, los vómitos y la diarrea (Cabrerizo et al, 2020). Algunas de las evidencias de la presencia del SARS CoV-2 en 
el agua residual se pueden ver en Medema et al, 2020; Giordana et al, 2020; Nemudryi et al, 2020; Randazzo et al, 2020; Wu et al, 2020 y Wurtzer et al, 2020. Estas evidencias, como las encontradas en el río Lambro en el área metropolitana de Milán, Italia, se están estudiando, entre otros objetivos, para monitorear la posible difusión de la pandemia de la COVID- 19 (Giordana et al, 2020). El tema del SARS-CoV-2 y sus implicaciones en los recursos hídricos de México, cobra relevancia por su relación con las descargas de aguas residuales (especialmente las no tratadas), debido a que la inmensa mayoría de las descargas de aguas servidas de las grandes ciudades, cabeceras municipales, comunidades de zonas urbanas y rurales en México se realizan a los ríos, arroyos, lagos, lagunas y embalses de presas, con riesgos potenciales para el medio ambiente y la salud humana, especialmente en dos de los grandes sectores hídricos de la nación: I. El suministro de agua para el consumo humano y usos domésticos y 2 . El riego agrícola para la producción de alimentos. El primer sector aporta el servicio de suministro de agua a más de 34,000 centros de población y comunidades anexas, y el segundo proporciona buena parte de los productos y alimentos agrícolas que se consumen en el país.

\section{Contaminación con aguas residuales de ríos y arroyos en México}

En México existen 32 ciudades capitales, 2457 municipios y 3 I,873 ejidos y comunidades rurales, que en total suman 34,362. La inmensa mayoría carece de plantas de tratamiento de aguas residuales (PTAR). Para contextualizar la magnitud de este problema, se debe destacar que en el año 2017 el país solo contaba con 2,526 plantas municipales de tratamiento en operación y al cierre de 2018 se incrementó a 2,540 (CONAGUA, 2018). Esto significa que la inmensa mayoría de arroyos, ríos, lagos, lagunas, vasos de presas y zonas marinas reciben las descargas de aguas residuales no tratadas de manera permanente. De acuerdo con lbarrán et al, (2017) en el año 2006 el $74 \%$ de los ríos de México estaban contaminados, con distintos grados de polución. En aquellos años solo se trataban el $20 \%$ de las aguas residuales (Ibarrán et al, 2017). Después de 14 años, la situación ha empeorado. A modo de ejemplo se enuncian las siguientes cifras: partiendo de la existencia de 34362 ciudades y poblaciones en México y considerando que solo se dispone de 2540 PTAR construidas, se infiere que falta por construir, por lo menos, 32822 sistemas de tratamiento de aguas residuales, por lo tanto, sin menoscabo de un error apreciable en las estimaciones y considerando que actualmente la inmensa mayoría de las ciudades y poblaciones descargan sus aguas a corrientes superficiales o cuerpos de agua, es fácil deducir que más del $90 \%$ de los ríos asociados a estas descargas están siendo contaminados. Debe hacerse notar que de las 2540 PTAR construidas en México, que 
la CONAGUA reportó en el año 2018 , un alto porcentaje no está en funcionamiento. A modo de ejemplo se expone el caso de Chiapas, que de acuerdo al inventario de PTAR de la CONAGUA (2016), existían hace casi un lustro 76 PTAR en todo el Estado. Un inventario posterior realizado en el año 2018 cifró el número de PTAR en I I8. Actualmente, después de un recuento más cuidadoso (sin que los datos sean definitivos) el Instituto Estatal del Agua (INESA) de Chiapas, estima que a la fecha existen 294 PTAR en todo el Estado (Moguel, 2020), sin embargo, solo funcionan correctamente dos (de acuerdo a las normas de operación). Es decir, más del $99 \%$ del total plantas de tratamiento de aguas residuales en el Estado de Chiapas no están en operación, por diferentes razones, entre otras se enuncian los siguientes: problemas en el sistema electromecánico; fallas en los equipos de bombeo; desperfectos en la cribas; deficiencias en los reactores aerobios; mal funcionamiento de los sedimentadores; inadecuada operación de los digestores; carencia de suministro de energía eléctrica (por falta de pagos); problemas en los accesorios y partes hidráulicas, por el inadecuado diseño o franco deterioro por no disponer de un programa y recursos financieros para el mantenimiento; problemas de formación de espumas y toxicidad del afluente; abandono de las PTAR (muchas de ellas están sin operar aún después de ser inauguradas). Otras tantas, desde hace varios años, en espera de su rehabilitación (como es el caso de la PTAR de la ciudad de Comitán de Domínguez). Algunas más que ya fueron rehabilitadas recientemente no están en operación (como es el caso de la PTAR de Pacú, en el municipio de Suchiapa). Por otra parte, se debe destacar que muchas PTAR fueron mal diseñadas y nunca iniciaron su operación. Otras, fueron construidas por empresas que no cumplían con el perfil profesional adecuado.

\section{Contaminación del suelos y cultivos con aguas residuales}

Un caso relevante de contaminación de suelos y cultivos a nivel nacional es el del Valle del Mezquital (VM) en el estado de Hidalgo, que recibe un poco más de $50 \mathrm{~m}^{3} / \mathrm{s}$ de aguas residuales no tratadas de la Zona Metropolitana de la Ciudad de México (ZMCM). Esta caudal procede de tres fuentes: el Gran Canal del Desagüe, el Interceptor Poniente y el Emisor Central. Buena parte de ese caudal se almacena en el vaso de la presa Endhó (Lesser et al, $20 \mathrm{II}$ ). Las aguas residuales que se reciben desde hace más de 100 años de la ZMCM se utilizan para regar 90 mil ha, con el fin de hacer producir cultivos como maíz, alfalfa, frijol, cebada y trigo, entre otros (Vázquez et al, 200 I). Existen resultados de muchas investigaciones que han evidenciado los diversos problemas generados por el uso de aguas contaminadas en la zona de riego del VM, entre los más relevantes se pueden enunciar los siguientes (García, 2019): a. Contaminación ambiental, que ha afectado no 
solo al entorno natural sino en mayor medida a las localidades que tienen un alto grado de marginación, b. Baja disponibilidad de agua apta para el consumo humano, c. Deterioro de la salud de la población, d. Contaminación y degradación del suelo, y e. Contaminación de los mantos acuíferos.

Así, Cajuste et al, (199I) y Flores et al, (1997) evidenciaron la contaminación del suelo y plantas con metales pesados en las zonas irrigadas delVM. Por su parte, Reyes et al, (2009) y Huerta et al, (2002) enunciaron que existe algún grado de contaminación en los suelos por el uso de aguas residuales en el VM. Además, Reyes et al, (2009 y Vázquez et al, (200l) comprobaron que la cantidad promedio de $\mathrm{Cd}$ que se acumula anualmente en el suelo es de $384 \mathrm{a} 640 \mathrm{~g} \mathrm{ha}^{-1}$. Estos autores afirmaron que, del valor de las relaciones entre el contenido de Cadmio y Níquel en las hojas, se puede inferir que esos metales se acumulan en el grano del trigo, lo que indica un riesgo potencial para la salud de los organismos consumidores de ese alimento básico. Por otra parte, debido a la movilidad de estos dos metales, tanto en el suelo como en algunas especies vegetales, recomendaron establecer criterios de calidad del suelo en función de la cantidad aceptable de metales que se puedan acumular en este sustrato, con el fin de minimizar los riesgos por exposición nociva a $\mathrm{Cd}$ y $\mathrm{Ni}$. No solamente el suelo y los cultivos están contaminados, también el acuífero delVM. Lesser et al (20l I) determinaron que, en sesenta y cinco pozos analizados, el sodio y los sólidos totales disueltos se encuentran por arriba del límite máximo permisible para el agua de consumo humano. Los fosfatos y el boro también están presentes en el agua subterránea en concentraciones altas, se detectó arsénico, fluoruros y plomo en concentraciones que superan el límite máximo permisible. En treinta de los setenta y cinco pozos de agua potable analizados bacteriológicamente, se detectaron coliformes totales y en varios de ellos coliformes fecales. Además de esta problemática, desde el mes de marzo de 2020 el VM está recibiendo el agua contaminada de la ciudad de México con altas probabilidades de tener material genético del SARS CoV-2, por las heces de los pacientes que se infectaron por esa enfermedad en toda la ZMCM.

En el caso de Chiapas, las aguas residuales sin tratamiento que se desfogan de la cuenca de la ciudad de San Cristóbal de las Casas se utilizan para el riego agrícola de hortalizas, aguas abajo del "túnel" de dicha ciudad. De acuerdo con el Instituto de Fomento a la Agricultura Tropical (IFAT), son aproximadamente 100 hectáreas de hortalizas las que se riegan con aguas residuales durante dos ciclos agrícolas en unas siete comunidades del municipio. De esa superficie se sostienen económicamente 200 familias de las siguientes comunidades: Pozo Colorado, Guadalupe el Túnel, La Lagunita, El Aguacate, Sacualpa, Duraznal y Matasano, las que, por carecer del vital líquido, riegan sus hortalizas con las aguas de desecho sin tratamiento de la ciudad de San Cristóbal de las Casas. En esa superficie irrigada con 
aguas residuales sin tratar se produce papa, acelga, zanahoria, ajo, betabel, calabacita, cebolla, cilantro, coliflor, brócoli, tomate, chayote, chícharo, chile, frijol ejotero, haba, jitomate, lechuga y rábano. Se cultivan en promedio 30 hectáreas de papa, con una producción aproximada de 450 toneladas por ciclo agrícola. Los otros cultivos con mayor superficie son el repollo (I5 hectáreas, que produce 180 toneladas por ciclo), el brócoli (I 0 hectáreas, que producen 100 toneladas por ciclo) y lechuga ( 10 hectáreas, que producen 80 toneladas por ciclo). De acuerdo al IFAT en las 100 hectáreas regadas con aguas residuales no tratadas, se cosechan II 70 toneladas de hortalizas dos veces al año. La producción de hortalizas de distribuye en todo el estado de Chiapas (Inforural, 2008). Del mismo modo que el VM, el suelo y el agua de la zona de riego aguas abajo del túnel de San Cristóbal de las Casas tiene un riesgo potencial alto de contener y transportar material genético de SARS CoV-2. Por lo tanto, deben desarrollarse las investigaciones científicas pertinentes para determinar los riesgos al medio ambiente y a la salud humana, no solo de los productores de la zona y sus familias, sino también de los consumidores.

\section{Contaminación de reservas naturales y presas}

Reservas naturales. El Parque Nacional Lagunas de Montebello (PNLM) en el estado de Chiapas se localiza en la subcuenca RD30Gl Río Grande en la región hidrológica RH 30 Grijalva-Usumacinta. Desde el año 2002 empezó a notarse la contaminación de la Laguna Encantada con olores fétidos y mortandad de peces durante los meses de diciembre y enero (Cervantes, 2020). De acuerdo a Ávila (2007) el PNLM está siendo contaminado por los agroquímicos utilizados en las actividades agrícolas de la parte media de la subcuenca (Ávila, 2017), debido a que esa zona ha sido deforestada, sustituyendo el bosque por cultivos agrícolas, como se puede ver en las figuras 4 y 7 .

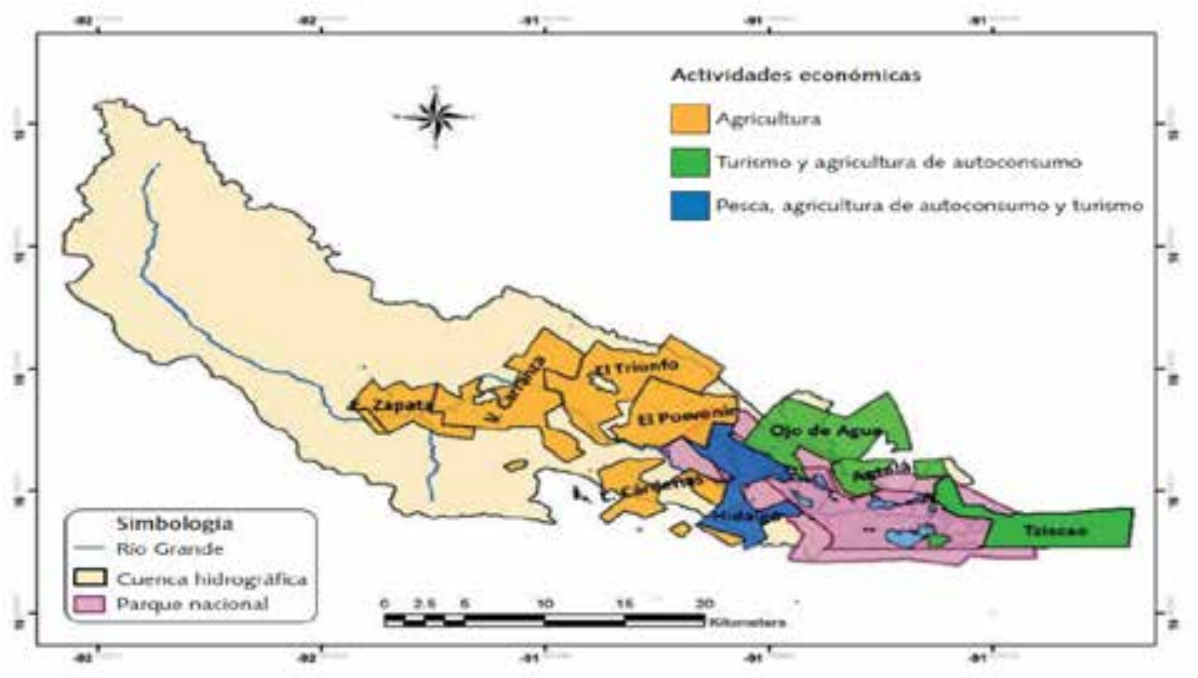

Figura 4. Actividades agrícolas en la parte media de la cuenca. Fuente: Ávila, 2017 
Sin embargo, en una conferencia reciente organizada por la Asociación Mexicana de Hidráulica, Cervantes (2020) afirmó que de los más de 50 lagos existente en el PNLM el 50\% de ellos (un poco más de 725 ha. de superficie lagunar lacustre, mostrada en la figura 5) están contaminados no solo por los agroquímicos, sino además por las aguas residuales no tratadas (figura 6) que escurren hacia la parte baja de la subcuenca y el arrastre de suelos, debido al proceso de deforestación que ha sufrido la subcuenca (ver figura 7).
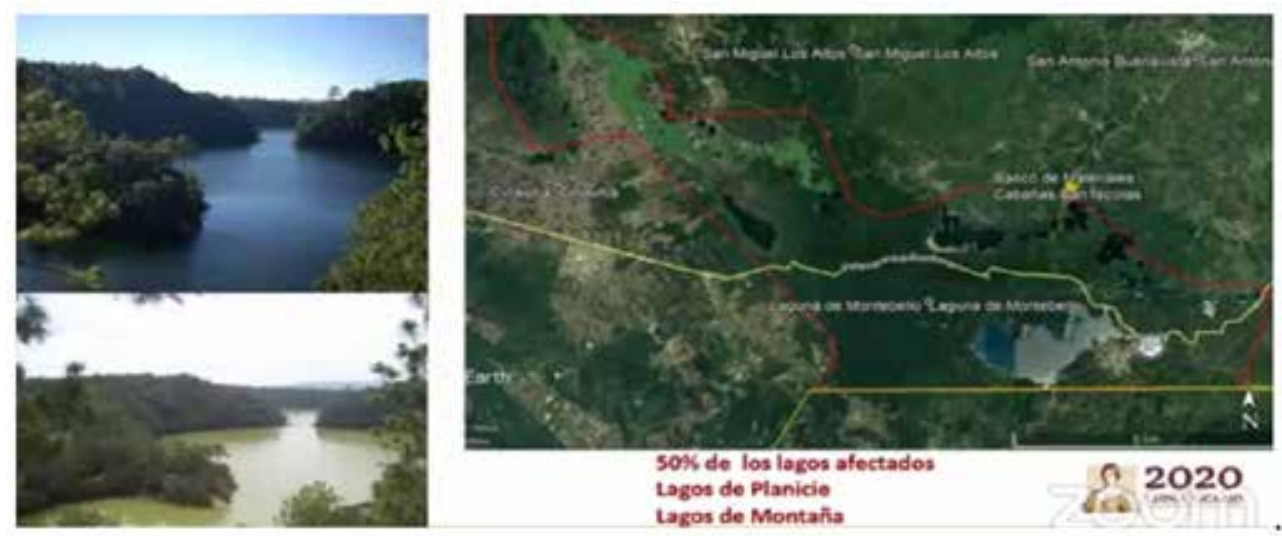

Figura 5. La Laguna Encantada y lagunas de la planicie con alta polución, en el PNLM. Fuente: Cervantes, 2020

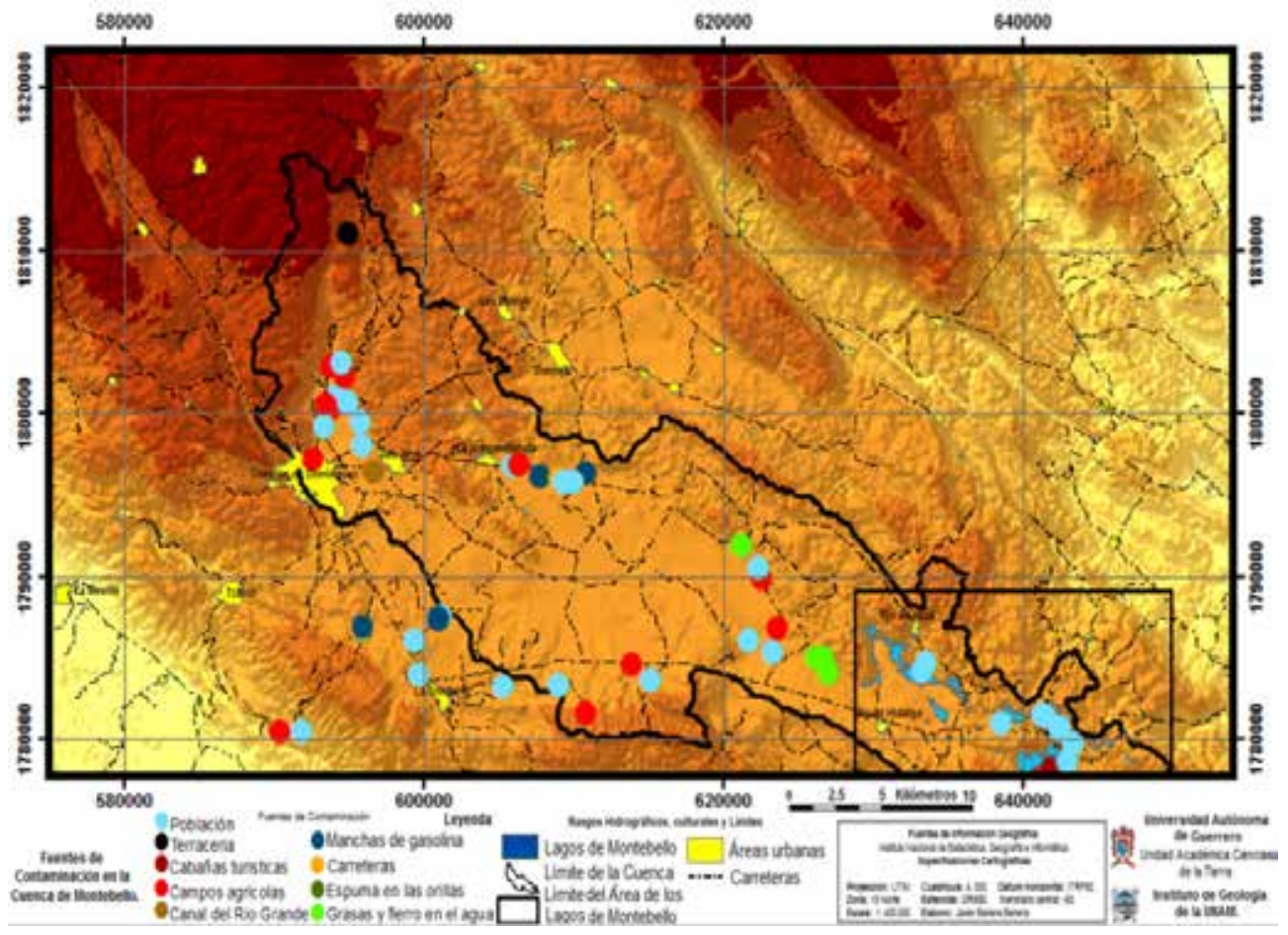

Figura 6. Sitios con diferentes tipos de contaminación, incluyendo coliformes fecales. Fuente: Bahena, 2014 
El proceso de deforestación de la subcuenca es irracional e irreversible, con una respuesta casi nula de las instituciones federales, estatales y municipales competentes. De acuerdo a Cervantes, ha sido reducido el $60 \%$ de la superficie de la masa forestal de los cuatro municipios de la subcuenca (figura 7), por lo tanto, el arrastre de sedimentos desde la parte media de la subcuenca hacia el PNLM es muy alto (oscilan entre 0.5 a 5 t/ha/año).

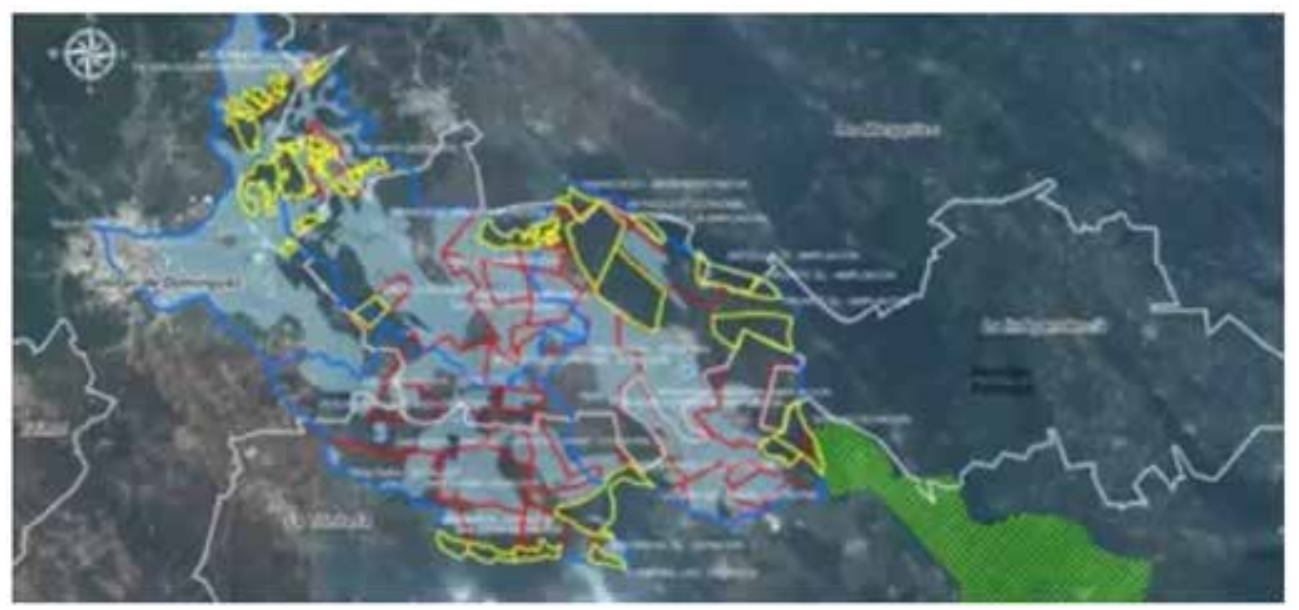

Figura 7. Zonas deforestadas de la subcuenca. En color verde se puede ver el PNLM. Fuente: Cervantes, 2020

La contaminación de las reservas naturales no es un caso único en el país, el lago de Chapala y el Lago de Pátzcuaro padecen una circunstancia similar en cuanto a la contaminación por la descarga de aguas residuales no tratadas.

El cañón del sumidero y la subcuenca del río Suchiapa. El cauce del cañón del sumidero (CS) que forma el embalse (vaso) de la presa Chicoasén, se está contaminando desde hace muchos años con residuos sólidos (RS) urbanos y rurales. Los RS urbanos (dispuestos en tiraderos a cielo abierto o los que se quedan en las calles de estos municipios) y los RS rurales de bosques y montañas deforestadas, son arrastrados por el viento y por los escurrimientos superficiales que los conducen hacia el cauce del Río Grijalva a través de una inmensa red hidrográfica, causando el denominado "tapón" (foto 3), que se forma por la acumulación de basura en una zona del CS en donde el flujo del embalse tiene un régimen hidráulico subcrítico, cuya característica fundamental de la corriente son los números de Froude inferiores a la unidad, junto al remanso hidráulico que se genera en el embalse (flujo retardado, tipo $\mathrm{MI}$ ). Ambas características hidráulicas ayudan a la formación del tapón hidráulico. Por otra parte, centenas de ejidos y comunidades de 16 alcaldías de Chiapas:Tuxtla Gutiérrez, Berriozábal, San Fernando, Osumacinta, Villaflores, Villacorzo, Suchiapa, Acala, Chiapa de Corzo, Venustiano Carranza, Totolapa, Chiapilla, San Lucas, Nicolás Ruiz, El Parral y Emiliano Zapata descargan sus aguas residuales no tratadas al 
Cañón del Sumidero. A modo de ejemplo se enuncia que: solo tres de los 16 municipios, Villaflores, Villacorzo y Parral, suman más de 30 comunidades ejidales que actualmente están contaminando al CS, no solo con basura sino también con aguas residuales a través de las subcuencas del río Suchiapa y de la subcuenca del río Santo Domingo (figura 8).

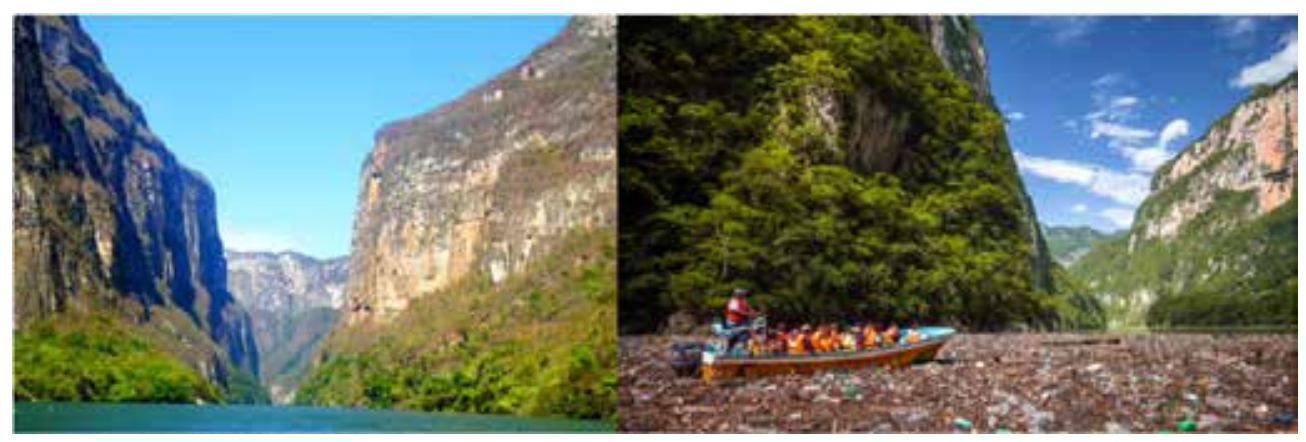

Foto 3. El Cañón del Sumidero limpio y con basura en el "Tapón”.

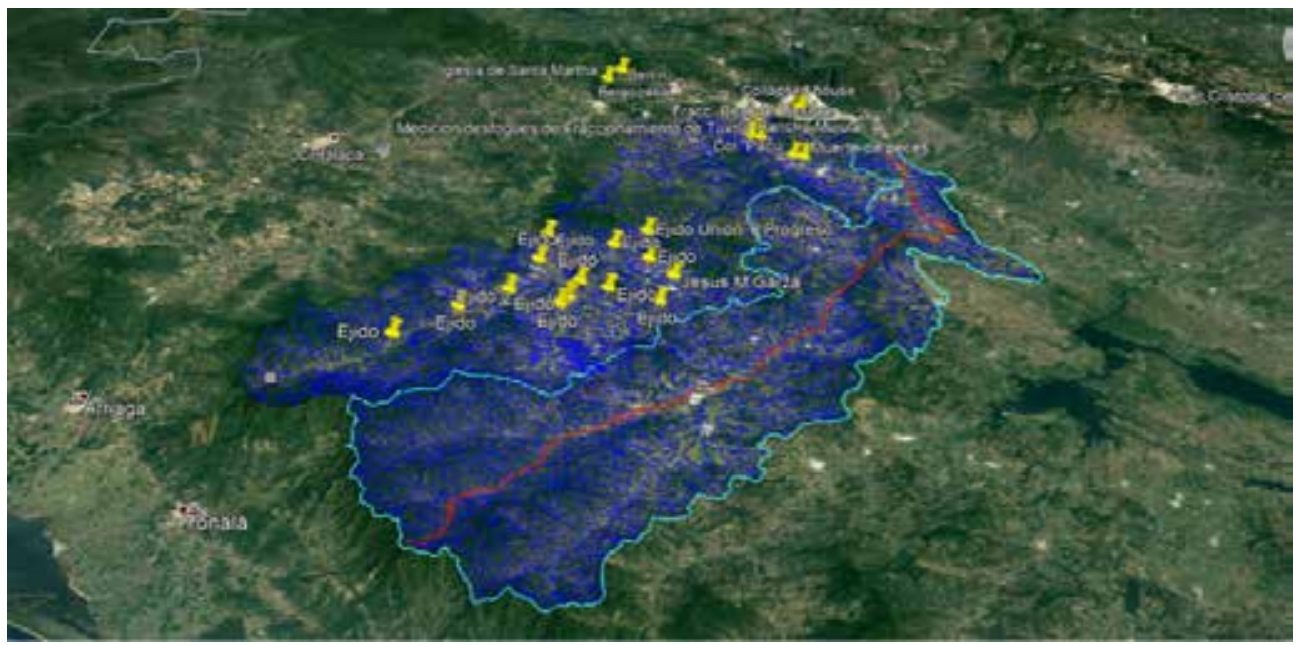

Figura 8. Subcuencas del río Suchiapa y Santo Domingo. Fuente: Google maps

Tiempo de sobrevivencia del coronavirus en aguas no contaminadas y residuales, a diferentes temperaturas

De acuerdo con la experiencia de la pandemia del SARS CoV-2, se estima que la principal forma de transmisión directa de los coronavirus de humano a humano, es a través de las gotitas de saliva expulsadas por tos, estornudos y la transferencia de fluidos salivales a través de los besos. Por ahora hay información limitada sobre la transmisión del virus al humano a través del medio ambiente (Gundy et al, 2008), exceptuando la hipótesis del transporte e inhalación de partículas PM2.5-10 con coronavirus adheridos a éstos en ambientes cerrados y contaminados. 
Sin embargo, como ya se ha demostrado en este ensayo, hay evidencia científica de la presencia del SARS CoV-2 en aguas residuales, ríos y arroyos. Intentando contribuir en este campo del conocimiento Gundy et al (2008) estudiaron la supervivencia de tres tipos de virus en "agua de grifo filtrada y sin filtrar a $4{ }^{\circ} \mathrm{C}$ y $23^{\circ} \mathrm{C}$ y "aguas residuales a $23^{\circ} \mathrm{C}$ ": I. Coronavirus de peritonitis infecciosa felina (FIPV), 2. Coronavirus humano 229E (HCoV) y 3. Poliovirus I (PV-I).

Algunos años antes de los experimentos de Gundy et al, (2008), John et al, (2005), Melnick et al, (1980) y Sobsey et al, (2003), indicaron que el factor que más influye en la sobrevivencia de los virus en el agua es la temperatura, el segundo factor es la presencia de materia orgánica y la cantidad de microorganismos aerobios. Se ha demostrado que la supervivencia de éstos disminuye con el aumento de la temperatura, principalmente por la desnaturalización de proteínas y el aumento de la actividad de las enzimas extracelulares (Hurst et al 1980; John et al, 2005). Los resultados de Gundy et al, (2008) corroboran también el efecto de la temperatura como uno de los factores más relevantes en la sobrevivencia del coronavirus (HCoV) en el agua. En la figura 9 se muestra la tasa de reducción logarítmica de concentración del coronavirus $\mathrm{HCoV}$ en agua filtrada a $23^{\circ} \mathrm{C}$.

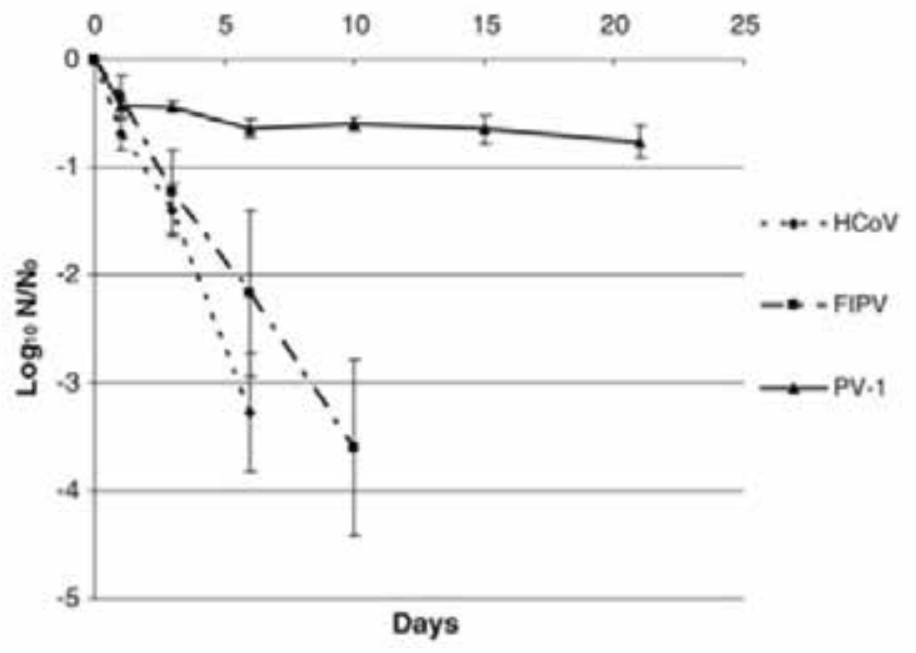

Figura 9. Reducción de la concentración del HCoV en agua filtrada a 23 oC. Fuente: Gundy et al, 2008

En la figura 10 se muestra la tasa de reducción logarítmica de concentración del coronavirus $\mathrm{HCoV}$ en agua filtrada a $4{ }^{\circ} \mathrm{C}$. 


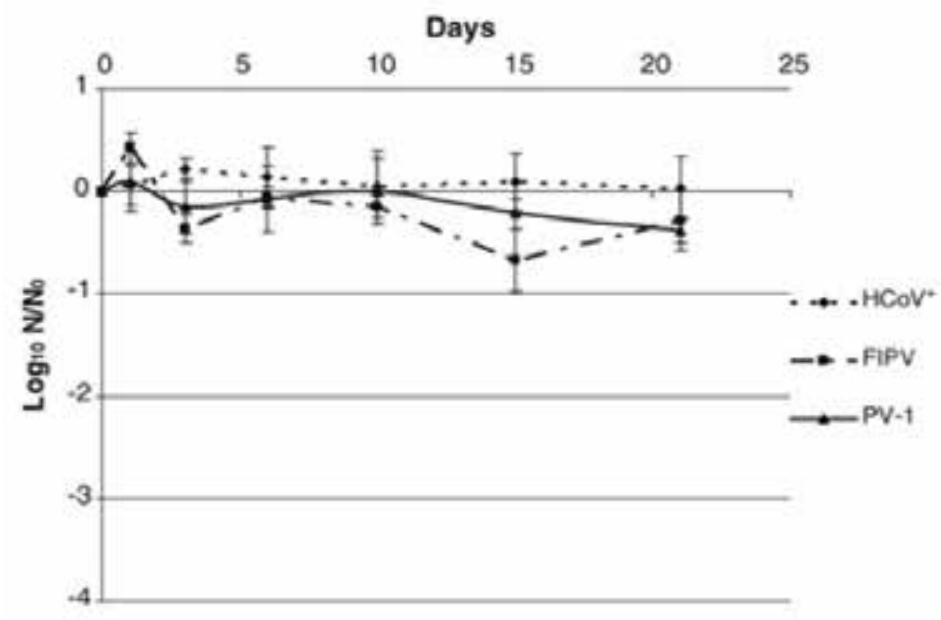

Figura 10. Reducción de la concentración del HCoV en agua filtrada a $4{ }^{\circ} \mathrm{C}$. Fuente: Gundy et al, 2008

En estas gráficas Gundy et al (2008) demuestran que aún en el agua filtrada y a bajas temperaturas, el coronavirus HCoV tiene más días de sobrevivencia. Por otra parte, los resultados del experimento de la sobrevivencia del coronavirus en aguas residuales de Gundy et al, demostraron que el $\mathrm{HCoV}$ logró sobrevivir hasta 3 días en ese medio (en el día número 3 la reducción fue del 99.9\%). Esta sobrevivencia es comparable con los datos del SARS-CoV obtenidos por Wang et al, (2005a, b). Además, sugieren que la sobrevivencia del coronavirus en aguas residuales primarias tuvo un tiempo ligeramente mayor que el agua residual secundaria, debido a la mayor concentración de sólidos en suspensión.

La filtración o no del agua también aumenta o disminuye la carga viral. De acuerdo con los resultados obtenidos por Gundy et al,(2008) la inactivación del coronavirus fue mayor en el agua filtrada que en el agua sin filtrar. En el agua de grifo filtrada se redujo o eliminó la influencia de las partículas de materia orgánicas y de las bacterias; así, a temperatura ambiente, solo se requieren 10 días para reducir hasta un $99.9 \%$ la presencia del coronavirus, mientras que en agua de grifo filtrada a $4{ }^{\circ} \mathrm{C}$ el virus requeriría más de 100 días para inactivarlo. Con relación a las aguas residuales, el HCoV sobrevivió más tiempo en el efluente primario sin filtrar que en el filtrado, debido a que en el primer caso los virus se adsorben a la materia orgánica y a los sólidos en suspensión, sin embargo, si las partículas de materia orgánica y los sólidos en suspensión se sedimentan, este puede ser un mecanismo para la eliminación de virus (Gundy et al, 2008). 


\section{CONCLUSIONES}

Durante la pandemia de la COVID-19 se han encontrado evidencias de la presencia del ARN del SARS COV-2 en aguas residuales no tratadas y en algunos ríos del mundo. Sin embargo, se necesitan más estudios para comprobar el tiempo de sobrevivencia del virus y su efectividad para contaminar al medio ambiente (suelo, aire, agua) y a los seres humanos. Wang et al, (20I8) afirmaron que las PTAR convencionales (basadas en la desinfección con ozono antes de la disposición final del agua) demostraron ser eficaces en la eliminación de la carga viral para muchos grupos de virus, entre otros: adenovirus, norovirus, sapovirus, parechovirus, virus de la hepatitis E, astrovirus, pecovirus, picobirnavirus, parvovirus y gokushovirus. El tratamiento convencional redujo las concentraciones virales, con la excepción de adenovirus y parvovirus, cuya eliminación fue menos eficaz, sin embargo, para el caso específico del SARS-CoV-2 existen pocos datos disponibles al respecto.

Giordana et al, (2020) estudiaron la sobrevivencia del SARS CoV-2 en ríos $y$ en aguas tratadas y sin tratar en una PTAR en el área metropolitana de Milán, Italia, utilizando las pruebas de PCR (Water SARS-CoV-2 RT-PCR Test). La PCR es un test de reacción en cadena de la polimerasa de transcripción inversa (RT-qPCR) que detecta y cuantifica el ARN del virus SARS-CoV-2 en aguas residuales no tratadas. Después del análisis filogenético del genoma del virus, se demostró que éste pertenece a la cepa más difundida en Europa y es similar a otra cepa encontrada en Lombardía. Los resultados de las investigaciones de estos autores afirman que la PCR de las aguas residuales sin tratar resultó positivo, mientras que el de las aguas tratadas resultó negativo (esto no omite la posibilidad de que copias virales del SARS CoV-2 estén presentes en la salida de las PTAR, en concentraciones bajas). La tasa de positividad de las pruebas de PCR en las muestras de agua sin tratar, disminuyó después de ocho días, mostrando que la efectividad del virus no siempre fue significativa, por lo tanto, esa investigación sugiere que la contaminación de las aguas residuales con SARS CoV-2 en la PTAR estudiada no tiene alto riesgo. Por otra parte, los resultados de las pruebas de PCR en un río de la zona metropolitana de Milán fueron positivos (debido a la descarga probable de aguas residuales no tratadas), sin embargo, el riesgo de contaminación por el virus fue mínima. Sin embargo, es necesario realizar más investigaciones al respecto.

Dada estas circunstancias e incertidumbres, las instituciones del sector hídrico de México, así como los centros de investigación y universidades, deben impulsar de forma conjunta a través de redes, proyectos para estudiar la sobrevivencia del SARS CoV-2, así como los riesgos potenciales de la presencia del ARN de este coronavirus en el agua potable de todos los organismos operadores del país, en el agua de riego, en lagos, lagunas y 
embalses de presas contaminadas por aguas residuales no tratadas. En el caso de México, es más urgente aún, porque más del $90 \%$ de sus ríos reciben descargas de aguas residuales sin tratar (con la presencia probable del ARN del SARS CoV-2 desde que empezó la pandemia hasta que esta dure, con sus posibles rebrotes), sumado a residuos sólidos urbanos, residuos sólidos rurales por la deforestación de selvas y bosques y cambio de uso de suelo.

Como ya se ha afirmado, en México solo existen 2,540 plantas de tratamiento y un alto porcentaje de éstas no operan, por lo que las aguas residuales no tratadas se descargan a los cuerpos de agua de la nación, violando la Ley de Aguas Nacionales (LAN). Existe una irresponsabilidad gubernamental federal, estatal y municipal en estas acciones. La LAN es taxativa en varios artículos en cuanto a los permisos para las descargas, la contaminación, el tratamiento de las aguas residuales, así como las sanciones respectivas (3 fracción XL apartado b; 7 fracción VII; 2 I fracción VIII; 23, 29 Bis fracción II; 86 fracciones IV, VIII y IX), pero en México esta ley no se cumple. Los Consejos de Cuenca en todas las Regiones Hidrológicas del país, tampoco realizan el trabajo que se les encomienda según el artículo 13 bis 3, fracción X: “...contribuir al saneamiento de las cuencas, subcuencas, microcuencas, acuíferos y cuerpos receptores de aguas residuales para prevenir, detener o corregir su contaminación".

Es de especial interés la violación del artículo 29 Bis 2 fracciones IV y $\checkmark$ que enuncia:

...Se suspenderá la concesión o asignación para la explotación, uso o aprovechamiento de aguas y bienes nacionales a cargo del Ejecutivo Federal, independientemente de la aplicación de las sanciones que procedan, cuando el usufructuario del título: descargue aguas residuales que afecten o puedan afectar fuentes de abastecimiento de agua potable o a la salud pública y así lo solicite la Procuraduría, o la Autoridad del Agua, y no cumpla con las condiciones o especificaciones del título de concesión o asignación...

Ningún Estado, Ayuntamiento Municipal y Ejido del país ha sido sancionado por violar esta ley, ni se le ha revocado la concesión por violar el artículo 29 bis 4 fracción III y X, a la vez. Tampoco hay castigos y sanciones para personas físicas, morales e instituciones que violan el artículo 86 bis 2 que enuncia:

...Se prohíbe arrojar o depositar en los cuerpos receptores y zonas federales, en contravención a las disposiciones legales y reglamentarias en materia ambiental, basura, materiales, lodos provenientes del tratamiento de aguas residuales y demás desechos o residuos que, por efecto de disolución o arrastre, contaminen las aguas de los cuerpos receptores, así como aquellos desechos o residuos considerados 
peligrosos en las Normas Oficiales Mexicanas respectivas. Se sancionará en términos de Ley a quien incumpla esta disposición.

No hay sanciones. México, en el tema de la aplicación de la ley, es un país de letra muerta. No se hace valer por la impunidad histórica y endógena de las instituciones nacionales y de los que, en la temporalidad respectiva, la representan; esto se refleja en todo el país, y también en las instituciones del sector ambiental e hídrico. La que rige este último sector y que fue creada en el año de 1989, está actualmente en crisis, sin rumbo, ni orientación, sumida en la corrupción, incluso de funcionarios menores. Debería resurgir como cabeza de sector, como Secretaría Nacional del Agua o Secretaría de los Recursos Hidráulicos.

A todas estas circunstancias se suma con urgencia el tema de la presencia del ARN del SARS CoV-2 en las aguas residuales. Existen muy pocos estudios científicos en el mundo sobre la presencia del virus en el agua y sus riesgos potenciales (en el caso de México ninguno publicado, hasta la fecha, en alguna revista de relevancia internacional, sobre los riesgos de la presencia del ARN del SARS CoV-2 y otros coronavirus en el agua). Así, es necesario desarrollar protocolos científicos estandarizados para la toma de muestras en cada uno de estos sitios, entre otros: equipo de protección, hora de la toma, número de muestras, equipo de muestreo, definición de la metodología para la utilización de la PCR (u otras pruebas más apropiadas) en cada cuerpo de agua, de acuerdo a sus características físicas, químicas, biológicas, hidrostáticas e hidrodinámicas, para comprender mejor su comportamiento y definir con mayor precisión los riesgos potenciales que el virus tiene para el medio ambiente y el ser humano. A pesar de que el virus del SARS generó una epidemia en China en el 2002 y en el 2012, de que el MERS-CoV provocó una emergencia en países del Medio Este (Arabia Saudita), Giordana et al (2020), enuncian que actualmente existe un vacío sobre protocolos científicos para la toma de muestras de aguas en las PTAR o aguas residuales sin tratar (descargadas a la naturaleza). No existe un protocolo estandarizado no solo para la detección y cuantificación del SARSCoV-2, sino además para evaluar y determinar los riesgos al medio ambiente y al ser humano. Por lo tanto, es necesario desarrollar una metodología estandarizada para la vigilancia de aguas residuales y comprender las implicaciones de la presencia del SARS-CoV-2 en éstas. La ciencia y la tecnología tienen la única llave, no solo para entender las implicaciones del SARS CoV-2 en el agua, sino para minimizar los efectos de este virus sobre la vida humana. 


\section{REFERENCIAS}

Abcdust. (2020). ¿Cuál es el tamaño de un virión de Covid-19 en relación con el MP10-2.5?. Recuperado de: https://abcdust.net/cual-es-el-tamanode-un-virion-de-covid-19-en-relacion-con-el-mp10-2-5/?lang=es

Andersen KG, Rambaut A, Lipkin WI, Holmes EC, Garry RF. (2020). The proximal origin of SARS-CoV-2. Nat. Med. 2020:1-3.

Ávila, G.D. (2017). Conservación de los Lagos de Montebello. Coordinación de Estudios de Posgrado. Programa de Posgrado de Ciencias Biológicas. Universidad Nacional Autónoma de México. Ciudad de México.

Bahena, B. J. (2014). Cartografía temática de la cuenca hidrográfica del sistema lagunar de Montebello, Chiapas. Tesis de licenciatura. Unidad Académica de Ciencias de la Tierra Taxco el Viejo Guerrero. Universidad Autónoma de Guerrero. Taxco Guerrero, México.

BBC. (2020). Coronavirus: por qué covid-19 se llama así y cómo se nombran los virus y las enfermedades infecciosas. BBC News online. Recuperado de: https://www.bbc.com/mundo/noticias-51912089

Cabrerizo, M., Fernández, G. M. (2020). Detección de SARS-COV-2 en aguas residuales como herramienta de vigilancia y alerta rápida. Informe del Grupo de Análisis Científico de coronavirus del ISCIII (GACC-ISCIII). Madrid, España.

Cajuste, L.J., Carrillo, R.G., Cota, E.G., Laird, R.J. (1991). The distribution of metals from wastewater in the Mexican Valley of Mezquital: Water Air and Soil Pollution. Water, Air, and Soil Pollution 57-58(1), 763-771. DOI https://doi.org/10.1007/BFo0282940

Cervantes, B.O. (2020). Importancia y situación actual de la problemática de contaminación en el Parque Nacional Lagunas de Montebello. Conferencia online. Asociación Mexicana de Hidráulica. CDMX. Recuperado de: https://www.youtube.com/watch?v=vuD-NWYdD2c\&ab_channel=Proyect osHidraulicaUnach

Chen $Y$, Chen L, Deng Q, et al (2020). The presence of SARS-CoV-2 RNA in the feces of COVID-19 patients. J Med Virol. 2020;92(7):833-840. doi:10.1002/jmv. 25825

CDCP. (2020). Factor to consider when planning to purchase respirator from another country, including KN95 respirator from China. Center for Disease Control and Prevention (CDCP). Recuperado de:https://www. youtube.com/watch?v=w7tVnjrmAmc\&ab_channel=CentersforDisease ControlandPrevention\%28CDC\%29

CONAGUA. (2016). Inventario Nacional de Plantas Municipales de Potabilización y de Tratamiento de Aguas Residuales en Operación. Secretaría de Medio Ambiente y Recursos Naturales. Comisión Nacional del Agua, Ciudad de México, México. 
CONAGUA. (2018). Inventario Nacional de Plantas Municipales de Potabilización y de Tratamiento de Aguas Residuales en Operación. Secretaría de Medio Ambiente y Recursos Naturales. Comisión Nacional del Agua, Ciudad de México, México.

DTNext. (2020). Wuhan market shrimp seller may be coronavirus 'patient zero': Report. DTNext Recuperado de: https://www.dtnext.in/News/ TopNews/2020/03/28153255/1222189/COVID19-Wuhan-market-shrimpseller-may-be-patient-.vpf

Flores, L., Blas, G., Hernández, G., Alcalá, R. (1997). Distribution and sequential extraction of some heavy metals from soils irrigated with wastewater from Mexico City: Water Air and Soil Pollution. Water, Air, and Soil Pollution, volume 98(1-2), 105-117.

Folegatti, P,M., Ewer, K.J., Aley, P.K., Angus, B., Becker, S., et al (2020). Safety and immunogenicity of the ChAdOx1 nCoV-19 vaccine against SARS-CoV-2: a preliminary report of a phase $1 / 2$, single-blind, randomised controlled trial. The Lancet, Vol. 396, ISSUE 10249, P. 467-478. DOI:https://doi.org/10.1016/ So140-6736(20)31604-4

García, E. (2019). El agua residual como generadora del espacio de la actividad agrícola en el Valle del Mezquital, Hidalgo, México. Estudios Sociales Revista de Alimentación Contemporánea y Desarrollo Regional, Volumen 29, Número 54.

Giordana, S., Stefani F., Gigantiello, A., Polesello, S., Comandatore, F., Mileto, D., Maresca, M., Longobardi, C., Mancon, A., Romeri, F., Pagani, C., Moja, L., Gismondo, M., Salerno, F. (2020). Presence and vitality of SARSCoV-2 virus in wastewaters and rivers. medRxiv preprint doi: https://doi. org/10.1101/2020.05.01.20086009

Gorbalenya, A., Baker, S., et al (2020). Severe acute respiratory syndrome-related coronavirus: The species and its viruses - a statement of the Coronavirus. Study Group bioRxiv 2020.02.07.937862; doi: 10.1101/2020.02.07.937862

Gundy, P.P., Gerva, C.P., Pepper, I.L. (2008). Survival of Coronaviruses in Water and Wastewater. Food Environ Virol (2009) 1:10-14 DOI 10.1007/ s12560-008-9001-6

Huerta, L., Contreras-Valadez, R., Palacios-Mayorga, S., Miranda, J., CalvaVasquez, G. (2002). Total elemental composition of soils contaminated with wastewater irrigation by combining IBA techniques: Nuclear Instruments and Methods in Physics Research Section B: Beam Interactions with Materials and Atoms. Science Direct, 189(1-4), 158-162.

Hurst, C. J., Gerba, C. P., Cech, I. (1980). Effects of environmental variables and soil characteristics on virus survival in soil. Applied and Environmental Microbiology, 40, 1067-1079. 
IATA. (2019). Estadística del transporte aéreo mundial 2018. Comunicado No. 45. Tomado de: https://www.iata.org/contentassets/f8d2fbbfe266 4612a1e4e65a22422dc3/2019-07-31-01-sp.pdf

Ibarrán, M.E., Mendoza, A., Pastrana, C., Manzanilla, E. (2017). Determinantes socioeconómicos de la calidad. Región y sociedad, Año XXIX, No. 69.

Inforural. (2008). Riegan en Chiapas con aguas negras. Inforural. Recuperado de: https://www.inforural.com.mx/riegan-en-chiapas-con-aguas-negras/

John, D. E., Rose, J. B. (2005). Review of factors affecting microbial survival in groundwater. Environmental Science \& Technology, 39(19), 7345-7356.

Koury, M.J., Hirschhaut, M. (2020). Reseña histórica del COVID-19 ¿Cómo y por qué llegamos a esta pandemia? Acta odontológica venezolana. Edición Especial: COVID-19. Recuperado de: https://www.actaodontologica.com/ ediciones/2020/especial/art-2/

Lesser, C.L., Lesser I.J., Arellano, I.S., González, P.D. (2011). Balance hídrico y calidad del agua subterránea en el acuífero del Valle del Mezquital, México central. Rev. mex. cienc. Geol., vol.28 no.3 México.

Lescure FX, Bouadma L, Nguyen D, Parisey M, Wicky PH, Behillil S, et al (2020). Clinical and virological data of the first cases of COVID-19 in Europe: a case series. Lancet Infect Dis. Vol. 20, ISSUE 6, P.697-706. DOI:https://doi.org/10.1016/S1473-3099(20)30200-0

Li, W. et al (2005). Bats are natural reservoirs of SARS-like coronaviruses. Science. 2005 [consultado el 7 sep 2020] 310(5748). Disponible en: URL https://pubmed.ncbi.nlm.nih.gov/16195424/

Marty, A. M., Jones, M. K. (2020). The novel Coronavirus (SARS-CoV-2) is a one health issue. One Health. Consultado el20 mar 2020. Disponible en: URL doi:10.1016/j.onehlt.2020.100123

Medema, G., Heijnen, L., Elsinga, G., Italiaander, R., Brouwer, A. (2020). Presence of SARSCoronavirus-2 in sewage. medRxiv, 2020.03.29.20045880. OMS.

Melnick, J. L., \& Gerba, C. P. (1980). The ecology of enteric virusesin natural waters. CRC Critical Reviews in Environmental Control, 10, 65-93

Moguel, E.G (2020). Comunicación personal, realizada el 8 de septiembre de 2020. Instituto Estatal del Agua (INESA). Tuxtla Gutiérrez, Chiapas.

NGE. (2020). Fotografías reales del coronavirus bajo el microscopio. National Geographic España (NGE). Recuperado de: https://www.nationalgeographic. com.es/ciencia/fotografias-reales-coronavirus-bajo-microscopio_15335/1

Nemudryi, A., Nemudraia, A., Surya, K., Wiegand, T., Buyukyoruk, M., Wilkinson, R., Wiedenheft, B. (2020). Temporal detection and phylogenetic assessment of SARS-CoV-2 in municipal wastewater. medRxiv 2020.04.15.20066746. https://doi.org/10.1101/2020.04.15.20066746

Organización Mundial de la Salud (2020). Oficinas regionales de la Organización Mundial de la Salud. Recuperado de: http://158.232.12.119/ about/regions/es/ 
Organización Panamericana de la Salud (2020a). Actualización Epidemiológica Nuevo coronavirus (COVID-19). Hoja informativa de la Organización Panamericana de la Salud. Recuperado de: https://www.paho.org/sites/ default/files/2020-02/2020-feb-28-phe-actualizacion-epi-covid19.pdf (2020b). Entender la infodemia y la desinformación en la lucha contra la COVID-19. Hoja informativa de la Organización Panamericana de la Saludo. Recuperado de: file:///C:/Users/Profesor\%20Mundo/Downloads/ FS-Infodemic-covid-19-SPA.pdf

Pan Y, Zhang D, Yang P, Poon LLM, Wang Q. (2020). Viral load of SARS-CoV-2 in clinical samples. Lancet Infect Dis. 2020;20(4):411-412. doi:10.1016/ S1473-3099(20)30113-4

Peiris, JS., Lai, ST., Poon, LL., Guan, Y., Yam, LY., Lim, W., Nicholls, J., Yee, WK., Yan, WW., Cheung, MT., Cheng, VC., Chan, KH., Tsang, DN., Yung, RW., Ng, TK., Yuen, KY. (2003). Coronavirus as a possible cause of severe acute respiratory syndrome. Lancet 361:1319-1325.

RAE. (2001). Diccionario de la Real Lengua Española. Vigésima segunda edición. Tomo 1. Madrid, España.

Ramón, V.D. (2019). La causa por la que los vuelos llegan a durar hasta un $30 \%$ más. AH Atlántico hoy. Recuperado el 10 de septiembre de 2020 de: https://atlanticohoy.com/front/post/tag/ descubre-por-que-los-vuelos-llegan-a-durar-hasta-un-30-mas

Randazzo, W., Truchado, P., Ferrando, E.C., Simon, P., Allende, A., Sanchez, G. (2020). SARSCoV-2 RNA titers in wastewater anticipated COVID-19 occurrence in a low prevalence area. medRxiv 2020.04.22.20075200. https://doi.org/10.1101/2020.04.22.20075200

Reyes-Solís, I.E., Solís, C., Isaac-Olive, K., García, N.E., Andrade, E. (2009). Fractionation analysis of trace metals in humic substances of soils irrigated with wastewater in Central Mexico by particle induced X-ray emission: Microchemical. Journal, 91(1), 129-132.

Salaverría, R., Buslón, N. López, F., León, B., López, I., Erviti, C. (2020). Desinformación en tiempos de pandemia: tipología de los bulos sobre la Covid-19. El profesional de la información v. 29, n. 3. e290315. https:// doi.org/10.3145/epi.2020.may. 15

SGS. (2020). Actualización $n^{\circ}$ 43. Enfermedad por el coronavirus (COVID-19). Secretaría General de Sanidad (SGS). Dirección General de Salud Pública, Calidad e Innovación del Gobierno de España. Madrid, España.

Sobsey, M. D., \& Meschke, J. S. (2003). Virus survival in theenvironment with special attention to survival in sewage dropletsand other environmental media of fecal or respiratory origin. Report for the World Health Organization, Geneva, Switzerland,p. 70

Torres, L.J. (2020). ¿Cuál es el origen del SARS-CoV2? Rev. Med. Inst. Mex. Seguro Soc. $N^{\circ} S 1,2020$. 
Tzintzun, M.G., L. Rojas y A. Fernández. (2005). Las partículas suspendidas en tres grandes ciudades mexicanas. Gaceta ecológica, 74, 15-28 (2005)

Vázquez, A.A., Justin, C.L., Siebe, G.C., Alcántar, G.G., Isla, B.M. (2001). Cadmio, Níquel y Plomo en agua residual, suelo y cultivos en el Valle del Mezquital, Hidalgo, México. Agrociencia, 35(3):267-274.

Velapam, T.P. and Meyer, C.G. (2020). The COVID-19 epidemic. Trop Med Int Health. Consultado el 19 mar 2020] 25 (3) Disponible en: URL doi:10.1111/tmi.13383

Vijaykrishna D, Smith GJ, Zhang JX, Peiris JS, Chen H, Guan Y. (2007). Evolutionary insights into the ecology of coronaviruses. Journal Virol, 81:4012-4020.

Wang W, Xu Y, Gao R, et al (2020). Detection of SARS-CoV-2 in Different Types of Clinical Specimens. JAMA, 2020;323(18):1843-1844. doi:10.1001/ jama.2020.3786

Wang, X. W., Li, J. S., Guo, T. K., Zhen, B., Kong, Q. X., Yi, B., et al (2005a). Excretion and detection of SARS coronavirus and its nucleic acid from digestive system. World Journal of Gastroenterology, 11(28), 4390-4395.

Wang, X. W., Li, J. S., Jin, M., Zhen, B., Kong, Q. X., Song, N., et al (2005b). Study on resistance of severe acute respiratory syndrome-associated coronavirus. Journal of Virological Methods, 126, 171-177.

Wang, H., Sikora, P., Rutgersson, C., Lindh, M., Brodin, T., Björlenius, B., Larsson, D.G.J., Norder, H. (2018). Differential removal of human pathogenic viruses from sewage by conventional and ozone treatments. Int. J. Hyg. Environ. Health 221, 479-488. https://doi.org/10.1016/j. ijheh.2018.01.012

Wertheim, J., Chu, D., Peiris, J., Kosakovsky, S., Ponn, L. (2013). A Case for the Ancient Origin of Coronaviruses. Journal of Virology, Volume 87 Number 12 p. $7039-7045$.

WHo. (2020). Novel coronavirus-China. Who, Recuperado de: https://www. who.int/csr/don/12-january-2020-novel-coronavirus-china/en/

Woo PC, Lau SK, Huang Y, Yuen KY. (2009). Coronavirus diversity, phylogeny and interspecies jumping. Exp. Biol. Med. (Maywood) 234:1117-1127.

Wu, F., Xiao, A., Zhang, J., Gu, X., Lee, W., Kauffman, K., Hanage, W., Matus, M., Ghaeli, N., Endo, N., Duvallet, C., Moniz, K., Erickson, T., Pr, C., Thompson, J., Alm, E. (2020). SARSCoV-2 titers in wastewater are higher than expected from clinically confirmed cases. medRixiv 2020.04.05.20051540. https://doi.org/10.1101/2020.04.05.20051540

Wurtzer, S., Marechal, V., Mouchel, J.-M., Moulin, L. (2020). Time course quantitative detection of SARS-CoV-2 in Parisian wastewaters correlates with COVID-19 confirmed cases. medRxiv 2020.04.12.20062679. https:// doi.org/10.1101/2020.04.12.20062679 
Zhang JC, Wang S Bin, Xue YD. (2020). Fecal specimen diagnosis 2019 novel coronavirus-infected pneumonia. J Med Virol. 92: 680-682. https://doi.org/10.1002/jmv.25742

Zhang, W., Rong-Hui Du, Bei Li, Xiao-Shuang Zheng, Xing-Lou Yang, Ben $\mathrm{Hu}$, Yan-Yi Wang, Geng-Fu Xiao, Bing Yan, Zheng-Li Shi \& Peng Zhou. (2020). Molecular and serological investigation of 2019-nCoV infected patients: implication of multiple shedding routes. Emerging Microbes \& Infections, 9:1, 386-389, DOI: 10.1080/22221751.2020.1729071

Zhong NS, Zheng BJ, Li YM, et al (2003). Epidemiology and cause of severe acute respiratory syndrome (SARS) in Guangdong. People's Republic of China, in February, 2003. Lancet. 362(9393):1353-1358. doi:10.1016/ s0140-6736(03)14630-2.

Zhou, P., Yang, X.-L., Wang, X.-G., Hu, B., Zhang, L., Zhang, W., Shi, Z.-L. (2020). A pneumonia outbreak associated with a new coronavirus of probable bat origin. Nature. doi:10.1038/s41586-020-2012-7

Zhu N, Zhang D, Wang W, Xingwang Li, Yang B, Song J, et al (2020). A novel Coronavirus from patients with pneumonia in China, 2019. N Eng J Med, 2020; 1-7. doi: 10.1056/NEJMoa2001017 